\title{
Plasma 'cortisol' levels in right and left ventricular failure
}

\author{
C. K. CONNOLLY ${ }^{1}$ AND M. R. WILLS \\ From the Departments of Medicine and Chemical Pathology, Royal Free Hospital, London
}

SYNOPSIS Plasma 'cortisol' values are reported in 36 patients during or following right ventricular failure, arid 12 during or following left ventricular failure. In patients with right ventricular failure the normal circadian rhythm was abolished with elevation of midnight values. Disturbance of $G$ rhythm was less marked in left ventricular failure, although midnight values were usually raised. $\mathscr{C}_{\infty}$ Dexamethasone suppression of plasma 'cortisol' levels was abolished or reduced in right ventricular 응 failure. These results confirm our earlier findings and further support our contention that the disturbance of circadian rhythm is not due to a simple stress mechanism. The results are of $\mathbb{D}$ importance in the differential diagnosis of Cushing's syndrome based on plasma 'cortisol' values, if there is concomitant right ventricular failure.

In normal subjects there is a circadian rhythm of the concentration of cortisol in blood with a minimum about midnight and a maximum between 06.00 and 09.00 hours (Mills, 1966). In Cushing's syndrome this rhythm is abolished due to elevation of the midnight value (Doe, Vennes, and Flink, 1960; Ekman, Hakansson, McCarthy, Lehmann, and Sjogren, 1961). This alteration in rhythm is regarded as helpful in 'screening' for Cushing's syndrome (Ross, Marshall-Jones, and Friedman, 1966). Congestive cardiac failure may be associated with many of the clinical features of Cushing's syndrome, and, simultaneously with Knapp, Keane, and Wright (1967), we reported (Connolly and Wills, 1967a) abolition of the circadian rhythm in plasma 'cortisol' levels ('cortisol' is the result of the fluorimetric estimation by the method of Mattingly (1962) which gives results rather higher than the true cortisol level) with elevation of the midnight value in patients with congestive cardiac failure. These findings limit the value of plasma cortisol estimation in the differential diagnosis of Cushing's syndrome, when there is concomitant congestive cardiac failure.

We report here a study of the correlation of the disturbance in 'cortisol' circadian rhythm in patients during or following right ventricular failure, compared with the findings in a group of patients with left ventricular failure.

${ }^{1}$ Present address: St George's Hospital, Tooting Grove, London, S.W.17.

Received for publication 3 June 1969.

\section{MATERIALS AND METHODS}

Plasma 'cortisol' was measured by a minor modification of the Mattingly fluorimetric method (1962) for free plasma 11-hydroxycorticoids. Our normal range for subjects without endocrine disorders in hospital is 1 to $9 \mu \mathrm{g}$ per $100 \mathrm{ml}$ at 24.00 hours and 9 to $30 \mu \mathrm{g}$ per $100 \mathrm{ml} \stackrel{\circ}{\varnothing}$ at 09.00 hours with an increase of at least $75 \%$ on the 24.00-hour level. Where the increase was between 50 을 and $75 \%$ we considered that there was partial retention of the rhythm. A difference less than this was considered to be abnormal.

Patients were not studied on their first night of admission. No special precautions were taken about venepuncture except that specimens were collected with minimal stasis.

Forty-eight patients have been studied. Thirty-six presented with predominantly right ventricular failure. Twelve had left ventricular failure without evidence of $\mathrm{O}$ right ventricular failure. An attempt was made to study patients before and after complete recovery. This was $\frac{D}{0}$ possible in seven of the patients with right ventricular failure and in four with left ventricular failure. Patients $\widetilde{N}$ in chronic failure were studied at weekly intervals. Four patients, two with right and two with left ventricular $\tilde{O}$ failure, were studied only after evidence of the failure $\underset{\mathrm{N}}{\mathrm{W}}$ had resolved.

A semi-quantitative assessment of the degree of right ventricular failure was made. Up to three points were allotted each for $(a)$ raised jugular venous pressure, $(b) \stackrel{\infty}{\stackrel{D}{\rightarrow}}$ hepatomegaly, and $(c)$ oedema. The points were added to give a possible maximum total of 9 . We considered that a score of 3 or more indicated certain right ventri- $\frac{\vec{D}}{\mathbb{D}}$ cular failure. The details of the point score system are shown in Table I.

Pulmonary oedema, clinically of cardiac origin, was 598 
accepted as evidence of left ventricular failure. This was diagnosed by the presence of orthopnoea and basal rales at the time of taking the specimen. The diagnosis of pulmonary oedema was confirmed by a chest radiograph. No attempt was made to quantitate left ventricular failure. Results following acute left ventricular failure were all obtained within two to seven days of an attack.

\section{TABLE I}

SCORING OF DEGREE OF RIGHT VENTRICULAR FAILURE

\begin{tabular}{llll} 
Score (points) & $\begin{array}{l}\text { Jugular Venous } \\
\text { Pressure }(\mathrm{cm})\end{array}$ & $\begin{array}{l}\text { Hepatomegaly } \\
(\mathrm{cm})\end{array}$ & Oedema \\
\hline 1 & $0-5^{1}$ & $1-3^{2}$ & Slight \\
2 & $6-8^{1}$ & $4-6^{2}$ & Moderate \\
3 & 8 or more $^{1}$ & 6 or more & Severe
\end{tabular}

${ }^{1}$ Above sternal angle.

${ }^{2}$ Below costal margin.

\section{RESULTS}

In the patients with right ventricular failure, the midnight plasma 'cortisol' levels were raised. In the majority this was associated with abolition of the normal circadian rhythm. Figure 1 shows the relationship between the midnight plasma 'cortisol' values and the degree of right ventricular failure as assessed by our scoring system. The figure is based on 62 estimations of plasma 'cortisol' in the 36 subjects studied. In those in whom the failure had resolved (score 0 ), three out of eight values were still above the upper limit of our normal range, by $1 \mu \mathrm{g}$ per $100 \mathrm{ml}$ in two cases and by $5 \mu \mathrm{g}$ per $100 \mathrm{ml}$ in the other. In the latter a further estimation within seven days gave a normal result. In those with only minor evidence of failure (score 1 to 2), all but five of the 21 results were above the normal range, while in those with definite evidence of failure (score 3 or more) all the 29 values were above normal.

In the 36 patients with right ventricular failure, 48 estimations of the 09.00 hour plasma 'cortisol'

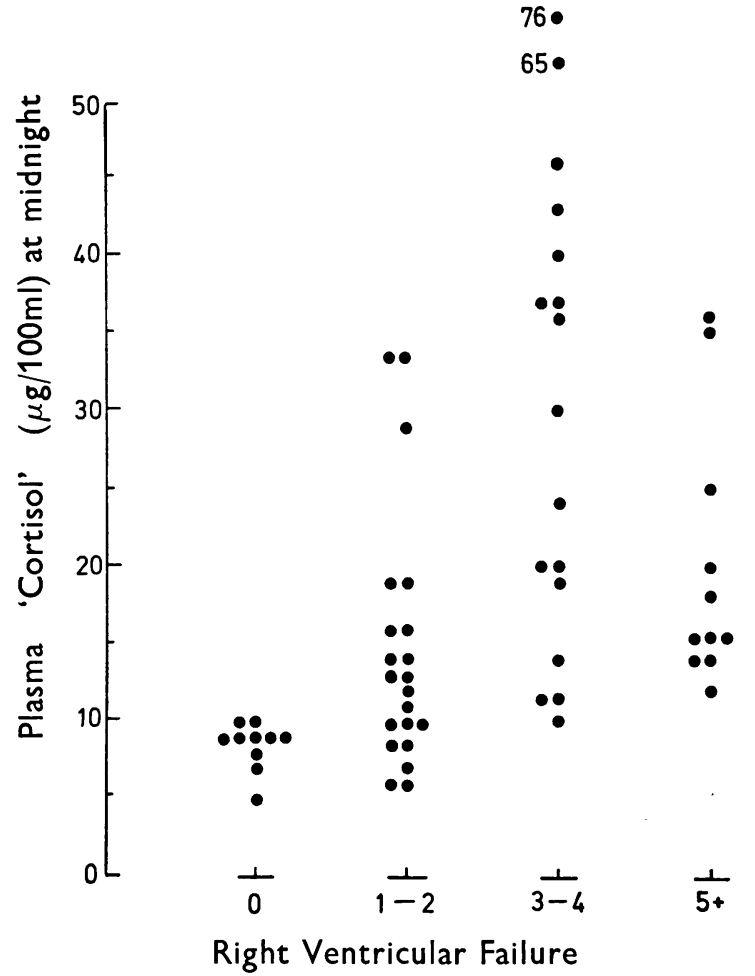

FIG. 1. The relationship between the degree of right ventricular failure and midnight plasma 'cortisol' values.

levels were available for comparison with the midnight values (Table II). In all but one of the 10 estimations on patients in whom failure had resolved (score 0 ), the circadian rhythm was normal. In the exception the rhythm had returned to normal by the next week. In the doubtful group (score 1 to 2 ) three out of 16 retained their rhythm and two partially

TABLE II

PLASMA 'CORTISOL' LEVELS AT 24.00 AND 09.00 HOURS IN PATIENTS WITH RIGHT VENTRICULAR FAILURE

\begin{tabular}{|c|c|c|c|c|c|c|c|c|c|c|c|c|c|c|}
\hline \multirow{3}{*}{$\begin{array}{l}\text { Right } \\
\text { Ventricular } \\
\text { Score } \\
0\end{array}$} & \multirow{3}{*}{$\begin{array}{l}\begin{array}{l}\text { Time } \\
\text { of Day } \\
\text { (hours) }\end{array} \\
24.00\end{array}$} & \multicolumn{13}{|c|}{ Plasma 'Cortisol' $(\mu \mathrm{g} / 100 \mathrm{ml})$} \\
\hline & & \multicolumn{5}{|c|}{ Normal Rhythm } & \multicolumn{2}{|c|}{ Partial Retention } & \multicolumn{6}{|c|}{ Rhythm Lost } \\
\hline & & 5 & 8 & 9 & 9 & 9 & & & \multicolumn{6}{|l|}{14} \\
\hline & 09.00 & 12 & 18 & 16 & 19 & 20 & & & \multicolumn{6}{|l|}{12} \\
\hline & 24.00 & 9 & 9 & 10 & 10 & & & & & & & & & \\
\hline & 09.00 & 20 & 33 & 20 & 21 & & & & & & & & & \\
\hline \multirow[t]{4}{*}{$1-2$} & 24.00 & 6 & 10 & 11 & & & 8 & 10 & 7 & 10 & 13 & 14 & 16 & 16 \\
\hline & 09.00 & 14 & 22 & 25 & & & 13 & 17 & 4 & 13 & 16 & 17 & 22 & 22 \\
\hline & 24.00 & & & & & & & & 19 & 19 & 29 & 33 & 33 & \\
\hline & 09.00 & & & & & & & & 17 & 19 & 34 & 22 & 35 & \\
\hline \multirow[t]{4}{*}{$3-4$} & 24.00 & 12 & 14 & 65 & & & 20 & & 10 & 12 & 19 & 20 & 24 & 30 \\
\hline & 09.00 & 31 & 26 & 156 & & & 32 & & 13 & 17 & 25 & 26 & 32 & 33 \\
\hline & 24.00 & & & & & & & & 36 & 37 & 37 & 43 & 76 & \\
\hline & 09.00 & & & & & & & & 41 & 23 & 45 & 42 & 33 & \\
\hline \multirow[t]{2}{*}{5} & 24.00 & & & & & & 12 & & 16 & 16 & 17 & 18 & 25 & 35 \\
\hline & 09.00 & & & & & & 19 & & 17 & 19 & 17 & 18 & 31 & 28 \\
\hline
\end{tabular}


retained rhythm. In definite moderate failure (score 3 to 4), three out of 15 retained their rhythm and one partially retained it. None of the seven patients with severe failure (score 5), had a normal rhythm, and only one showed partial retention of rhythm. Although 24.00-hour values were no higher in those with severe than in those with moderate failure (Fig. 1), the loss of rhythm was more consistent among the former. In patients studied before and after failure, the rhythm was shown to return to normal on recovery. This return to normal was seen in a subject whose right ventricular failure score had been as high as 6 .

A different pattern was seen in left ventricular failure (Fig. 2). The midnight plasma 'cortisol' levels were raised in all but one of 10 patients studied during an attack but the 'flattening' of the circadian rhythm was less marked than that seen in right ventricular failure. The 09.00 -hour plasma 'cortisol' showed an increase on the midnight value in all the eight patients in whom it was estimated. In five of these a circadian variation was fully retained. Two out of the three patients with an abnormal rhythm were moribund. In one patient with left ventricular failure who retained her rhythm the attack was followed after some days by right ventricular failure whereupon her rhythm was lost. Of the five patients studied after recovery from failure only one was

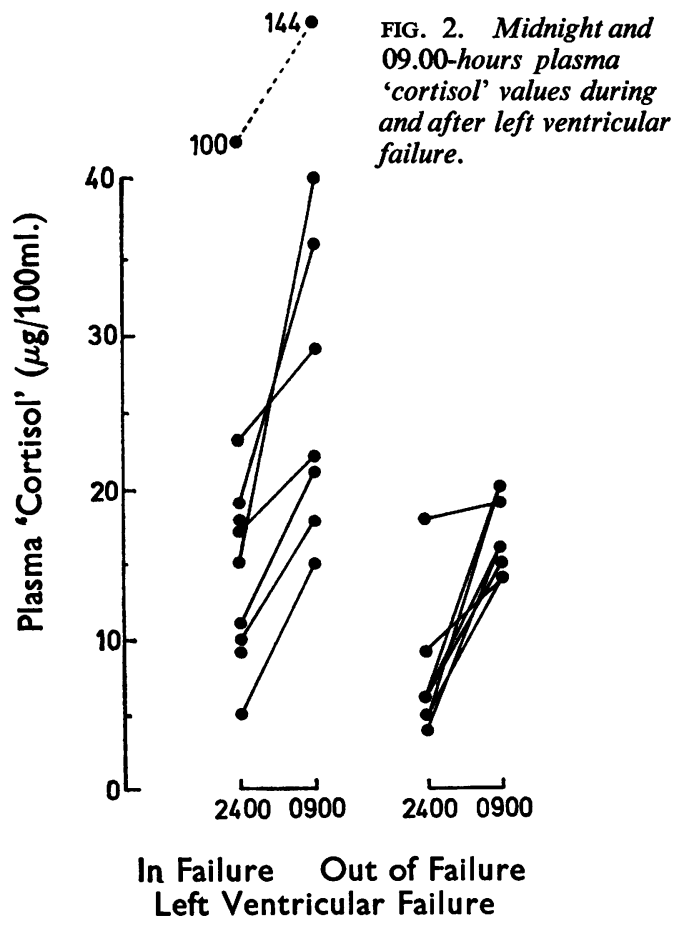

grossly abnormal, and one was slightly abnormal, plasma 'cortisol' at 24.00 and 09.00 hours of 9 and $14 \mu \mathrm{g}$ per $100 \mathrm{ml}$ respectively.

In six of the patients with right ventricular failure an attempt was made to suppress the plasma 'cortisol' levels with dexamethasone. We used the standard oral dosage of $0.5 \mathrm{mg}$ qid for two days, followed by $2 \mathrm{mg}$ qid for two days. Blood for plasma 'cortisol' estimation was collected on the third and fifth mornings of the test at 09.00 hours. The results are detailed in Table III. In three patients (A.S.,

TABLE III

DEXAMETHASONE SUPPRESSION TEST IN PATIENTS WITH RIGHT VENTRICULAR FAILURE

\begin{tabular}{llll} 
Patient & \multicolumn{2}{l}{ Plasma 'Cortisol' $(\mu \mathrm{g} / 100 \mathrm{ml})$ at 09.00 Hours } \\
\cline { 2 - 4 } & $\begin{array}{l}\text { Control } \\
\text { Value }\end{array}$ & $\begin{array}{l}\text { After Two Days of } \\
\text { Dexamethasone }\end{array}$ \\
\cline { 3 - 4 } & & $2 \mathrm{mg}$ per Day & $8 \mathrm{mg}$ per Day \\
\hline A.S. & 31 & 34 & 24 \\
John, J. & 45 & 70 & 1 \\
Jack, J. & 72 & 66 & 20 \\
S.O. & 25 & 26 & 23 \\
B.H. & 63 & 35 & 13 \\
L.B. & 17 & 9 & 6
\end{tabular}

1Patient's condition deteriorated and no specimen obtained.

John, J., and S.O.) there was little or no evidence of suppression of plasma 'cortisol'. In two patients (Jack, J. and B. H.) there was more evidence of suppression, particularly with the higher dosage of dexamethasone. In only one patient (L.B.) after the lower dose, did the plasma 'cortisol' level fall below that which might be accounted for by non-specific fluorescence. A further patient in predominantly right ventricular failure, who had periarteritis nodosa, was on long-term corticosteroids (prednisone $20 \mathrm{mg}$ per day). His plasma 'cortisol' values were 20 to $32 \mu \mathrm{g}$ per $100 \mathrm{ml}$ at 24.00 and 09.00 hours respectively despite the steroid therapy.

\section{DISCUSSION}

The results confirm our earlier report (Connolly and Wills, 1967a) and that of Knapp et al (1967) that the $\sigma$ circadian rhythm of plasma 'cortisol' is disturbed $N$ in patients with heart failure. The disturbance in N 'cortisol' rhythm is greater in patients with right ventricular rather than left ventricular failure, although the midnight levels of plasma 'cortisol' are raised in both. The disturbance in rhythm is seen in almost all patients with right ventricular failure and does not depend on the patient being seriously ill or distressed by his condition.

We have discussed previously (Connolly and Wills, $1967 \mathrm{a}$ and b) some of the factors that could account 
for this disturbance in rhythm. Of the various possibilities, Besser and Butler (1967) considered that our previous findings could be explained simply on the basis of stress without involving any other factor. The difference between patients with predominantly right and predominantly left ventricular failure suggested to us that stress was not the only factor. The patients in left ventricular failure were clinically more severely ill and emotionally more distressed but 'cortisol' rhythm was less disturbed than in those in right ventricular failure. A disturbance in sleep may upset the function of the pituitary-adrenal axis, but those patients in left ventricular failure had more disturbed nights than those in right ventricular failure. There was little difference in the drugs administered in the two groups of patients: normal and abnormal rhythms were both seen in patients on digoxin and on diuretics. Our normal range of 1 to $9 \mu \mathrm{g}$ per $100 \mathrm{ml}$ of plasma 'cortisol' at midnight was established mainly from patients in hospital with no evidence of endocrine abnormality. It is possible that this range does not represent a true basal midnight value, but we feel that it represents the normal range for patients in this hospital.

There is no evidence that the disturbance in circadian rhythm is caused by a failure of the normal mechanisms which control the clearance of cortisol from the plasma. In patients with chronic fluid retention due to cirrhosis of the liver, we have found plasma 'cortisol' values within our normal range, showing normal circadian variation and normal suppression with dexamethasone (Connolly and Wills, unpublished data). Moorhead and Varghese (personal communication) have studied patients with chronic anuric renal failure undergoing intermittent haemodialysis, and have found a persistence of the normal cortisol circadian rhythm in some of their patients, which suggests that the renal clearance of cortisol or its metabolites is not a critical factor in the maintenance of the normal circadian rhythm.

Although we have found that suppression of plasma 'cortisol' by a single small dose of dexamethasone may be modified by stress (Connolly,
Gore, Stanley, and Wills, 1968), it is usually accepted that the secretion of ACTH is entirely suppressed, even in conditions of stress, by the larger dose of dexamethasone employed here. The finding of an absence or reduction of suppression of 'cortisol' by dexamethasone in right heart failure was unexpected. It suggests either modification of the normal hypothalamo-pituitary mechanism for the production of $\mathrm{ACTH}$ or stimulation of the adrenal cortex by another substance. Cade, Shires, Barrow, and Thomas (1967) have reported abnormalities of circadian cortisol rhythms and of dexamethasone suppression in patients with hypertension due to renal artery stenosis. They suggested that this was due to direct general stimulation of the adrenal by angiotensin. We suspect that a similar mechanism involving this or another humoral element may operate in heart failure. The disturbance of rhythm is most consistent in right ventricular failure where there is a secondary increase in aldosterone secretion. Our results could equally well be explained by a similar stimulation at pituitary or hypothalamic level. Direct measurement of ACTH levels would be required to establish whether stimulation occurred at adrenal or higher levels.

We would like to thank Professor S. Sherlock, Drs N. D. Compston, C. D. Holdsworth, Cecil Symons, and A. G. Beckett for permission to study their patients.

\section{REFERENCES}

Besser, G. M., and Butler, P. W. P. (1967). Brit. med. J., 2, 446.

Cade, R., Shires, D. L., Barrow, M. V., and Thomas, W. L. (1967). J. clin. Endocr., 27, 800.

Connolly, C. K., Gore, M. B. R., Stanley, N., and Wills, M. R. (1968). Brit. med. J., 2, 665 .

-, and Wills, M. R. (1967a). Ibid, 2, 25 .

- - — (1967b). Ibid, 2, 640.

Doe, R. P., Vennes, J. A., and Flink, E. B. (1960). J. clin. Endocr., 20, 253.

Ekman, H., Hakansson, B., McCarthy, J. D., Lehmann, J., and Sjögren, B. (1961). Ibid, 21, 684.

Knapp, M. S., Keane, P. M., and Wright, J. G. (1967). Brit. med. J., $2,27$.

Mills, J. N. (1966). Physiol. Rev., 46, 128.

Mattingly, D. (1962). J. clin. Path., 15, 374.

Ross, E. J., Marshall-Jones, P., and Friedman, M. (1966). Quart. J. Med., 35, 149 . 